\title{
CIRCUMFERENTIAL PERIOSTEAL RELEASE IN THE TREATMENT OF CHILDREN WITH LEG-LENGTH INEQUALITY
}

\author{
G. P. WILDE, G. C. W. BAKER \\ From Harlow Wood Orthopaedic Hospital, Near Mansfield
}

\begin{abstract}
We present the results of $\mathbf{3 8}$ children with leg inequality treated by circumferential periosteal release. Leg-length discrepancy was expressed as a percentage of the longer limb. All patients showed a decrease in percentage difference at one year after operation, the mean difference dropping from $7.24 \%$ to $5.45 \%$. The size of the response was directly related to the age of the patient at operation, being more pronounced in the younger patients. The response was not related to sex, diagnosis, or rate of growth of the patient immediately preceding operation.
\end{abstract}

The correction of leg-length discrepancy has long been a challenging problem for the orthopaedic surgeon. Theoretically, the most desirable method of achieving equality is to stimulate growth in the short, usually abnormal, limb (Blount 1958). The first recorded attempts at such a procedure were those of von Langenbeck in 1869. Since then many methods have been employed to stimulate the growth of a short limb in both animals (Wu and Miltner 1937; Doyle and Smart 1963; Solá, Silberman and Cabrini 1963; Shiu and Wong 1964) and man (Barr, Stinchfield and Reidy 1950; Carpenter and Dalton 1956; Tupman 1960; Castle 1971; Petty, Winter and Felder 1974; Jenkins, Cheng and Hodgson 1975) and varying degrees of efficacy have been claimed.

In 1972 Crilly showed that growth of the radius in the immature chicken could be increased by circumferential division of the periosteum. His experiments have since been repeated in rats with similar results (Taylor and Warrell 1977), and in 1984 one of us presented the preliminary results of circumferential periosteal release in children with leg-length inequality (Baker 1984).

We now report on 38 patients who have undergone periosteal release at Harlow Wood Orthopaedic Hospital in the 10-year period 1975 to 1985, 22 of whom have achieved their maximum response.

\section{PATIENTS AND METHODS}

The 38 patients in this study were selected from referrals to the leg inequality clinic at Harlow Wood Orthopaedic Hospital. They were children who were considered to be

G. P. Wilde, FRCS, Orthopaedic Registrar

G. C. W. Baker, FRCS, Consultant Orthopaedic Surgeon

Harlow Wood Orthopaedic Hospital, Near Mansfield, Nottinghamshire NG18 4TH, England.

Requests for reprints should be sent to Mr G. P. Wilde.

(C) 1987 British Editorial Society of Bone and Joint Surgery $0301-620 \mathrm{X} / 87 / 5181 \$ 2.00$ too young for structural shortening but had an actual or forecast level of inequality of over $3 \mathrm{~cm}$ - one likely to cause clinical symptoms at maturity. The underlying causes of their inequality are shown in Table I. There were 18 boys and 20 girls and their age at operation was between 15 months and 13.5 years. The mean leg-length discrepancy pre-operatively was $3.8 \mathrm{~cm}$ (range 1.8 to $9.2 \mathrm{~cm})$.

Table I. Cause of leg inequality in the 38 patients

\begin{tabular}{ll}
\hline Diagnosis & Number of patients \\
\hline Lateral (fibular) hypoplasia & 15 \\
Whole body asymmetry & 5 \\
Femoral hypoplasia & 3 \\
Osteomyelitis & $3^{*}$ \\
Proximal femoral focal deficiency & 3 \\
CDH with upper femoral growth arrest & 2 \\
Multiple haemangiomas & 1 \\
Unknown aetiology & 6 \\
\hline * in femur, I in the tibia & $-\cdots$
\end{tabular}

Measurement. Leg inequality was measured at each attendance both with a tape measure, from the anterior superior iliac spine to the medial malleolus and heel, and by scanogram. The scanograms were measured from the top of the femoral head to the lower border of the lateral femoral condyle and the lateral border of the inferior articular surface of the tibia. Since the contour of the upper end of the tibia, especially in children, provides no fixed point for accurate definition, tibial length was expressed as the distance between the lower end of the lateral femoral condyle and the lower border of the tibia. These figures were used to calculate the discrepancy in leg length which was then expressed as a percentage of 
the length of the longer limb. By this means figures for the percentage difference in tibial, femoral and total lengths were obtained for each case (Fig. 1).

The concept of percentage difference in leg length as a means of expressing our results was adopted for a number of reasons. Firstly, it removes any errors due to magnification of the radiographic images, although these should be negligible with modern scanogram techniques. Secondly, it is a more realistic expression of the disability caused by the leg-length discrepancy than is the absolute difference in leg length. For example, a $3 \mathrm{~cm}$ difference would be considerably more disabling to a child of small stature than to a taller one, and this would be reflected in the values for percentage shortening. Thirdly, by comparing serial values of percentage difference, the relative significance of the leg inequality can be monitored and a better prediction of long-term disability obtained.

Treatment. Periosteal release was recommended for a growing child with a degree of leg-length inequality sufficient to cause disability (or expected to progress to that stage at maturity), and in whom a progressive discrepancy had been shown by at least two preoperative scanograms six months apart. All operations were performed or supervised by the senior author, who also carried out all the outpatient assessments. The scanogram measurements were all independently checked and remeasured prior to analysis of the results. Follow-up. Initially patients were reviewed at twomonthly intervals, but with experience this was modified to six-monthly attendances as this adequately demonstrated the response to surgery. All patients had a minimum follow-up of one year with a mean value of 32 months. Long-term data collection was continued until either skeletal maturity was reached or structural leglengthening, or some other procedure to affect leg length, was performed. For this reason data for postoperative periods of longer than five years is available in only nine patients.

Three of the 38 patients underwent a second periosteal release procedure on the same limb three to four years after the first operation, and the results from these second procedures are analysed separately.

\section{Operative technique}

The patient is placed supine on the operating table with a high thigh tourniquet applied after Esmarch exsanguination. The leg is cleaned and towelled with the whole limb exposed below the tourniquet.

Periosteal division is undertaken at the lower end of the femur through two short vertical incisions in the midmedial and lateral lines. The vasti are reflected anteriorly
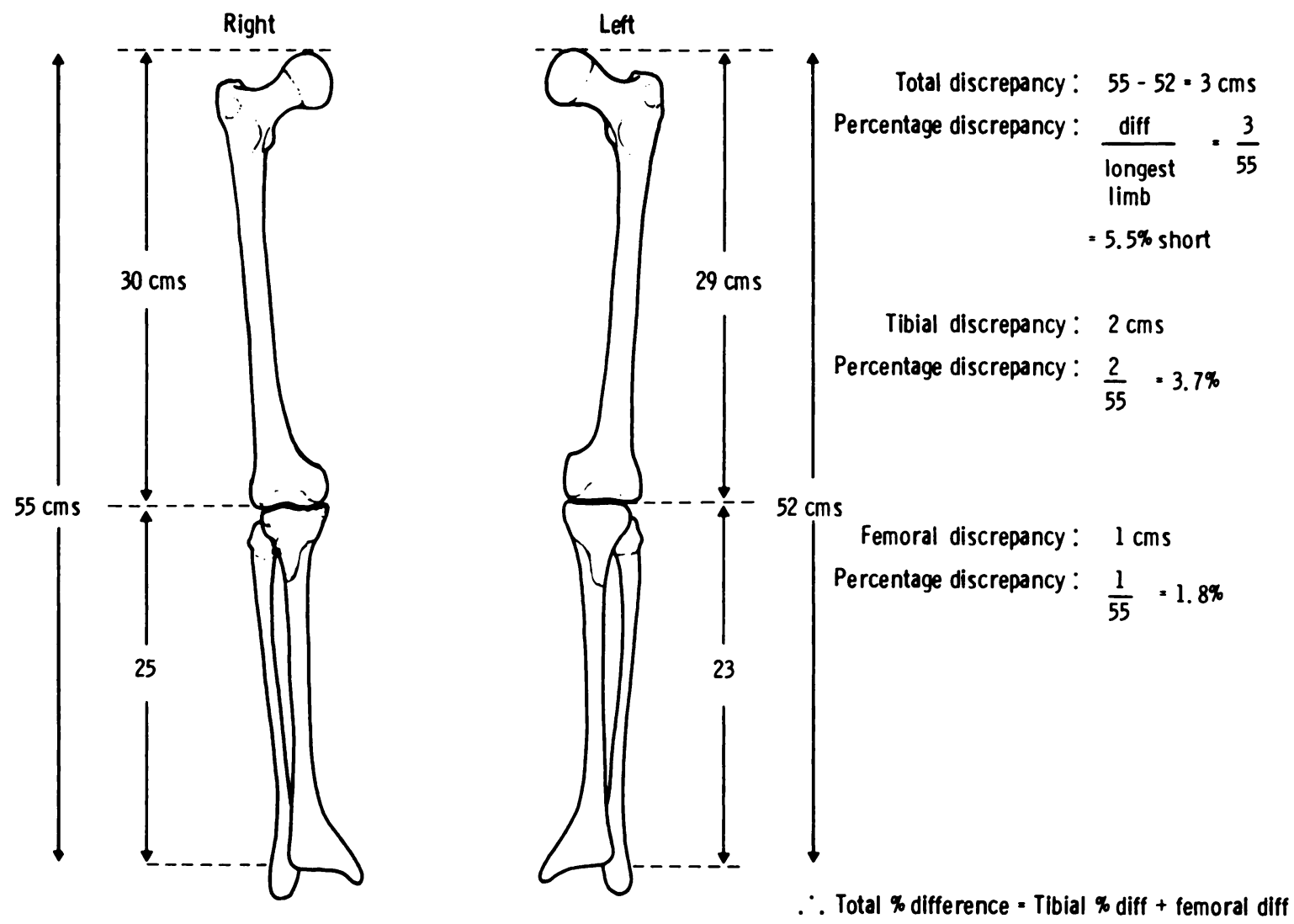

Fig. 1

Example showing how the percentage leg-length difference is calculated. 
to expose the distal femoral metaphysis and under direct vision a half-centimetre strip of periosteum is excised from the whole of its circumference. The cut edges of the periosteum are seen immediately to retract indicating complete division.

The tibia and fibula are also exposed at their lower ends through short medial and lateral longitudinal incisions. The lateral incision is made first over the anterior border of the subcutaneous surface of the fibula, just above the ankle. Through this a half-centimetre strip of periosteum is excised from the fibula and the interosseous membrane divided, allowing access to the lateral surface of the tibia. A mid-medial incision is then made to expose the remainder of the distal tibia and the circumferential excision of the periosteum is completed.

It is important to be absolutely sure that total circumferential excision has been achieved, as angular deformities may occur if division is incomplete (Houghton and Rooker 1979). All incisions are closed without drainage and no splintage is required. Mobilisation is permitted with full weight-bearing as soon as the child is comfortable, usually on the first or second day after operation. actual discrepancy of $0.8 \mathrm{~cm}$ (Table II). Three patients showed a slight increase in absolute discrepancy at one year but when expressed in percentage terms this still represented a reversal of the pre-operative trend of increasing percentage difference.

The response to periosteal release occurred with equal effect in both the tibia and fibula and in the femur, and the duration of stimulation was the same both above and below the knee. The response to surgery was considered to continue until the first set of data which showed a rise in the percentage difference, thus indicating a return to the pre-operative trend of increasing 'nequality. Not all patients in the study group have follow-up data for a long enough period to calculate a definite end-point as some of those more recently operated upon are still responding. The duration of the response is therefore only known in 22 of the original 38 patients. Of these, $10(46 \%)$ were still responding at two years and six $(27 \%)$ at three years. The maximum duration of response in our series was five years. The data for all the cases was used to construct a survival lifetable (Coldman and Elwood 1979) in an attempt to predict the duration of response. This showed that one

Table II. Postoperative mean difference in leg length

\begin{tabular}{llllll}
\hline $\begin{array}{l}\text { Time } \\
\text { (months) }\end{array}$ & $n^{*}$ & $\begin{array}{l}\text { Mean total } \\
\text { diff. } \pm \text { s.d. }\end{array}$ & $\begin{array}{l}\text { Mean \% leg } \\
\text { diff. } \pm \text { s.d. }\end{array}$ & $\begin{array}{l}\text { Mean \% femoral } \\
\text { diff. } \pm \text { s.d. }\end{array}$ & $\begin{array}{l}\text { Mean \% tibial } \\
\text { diff. } \pm \text { s.d. }\end{array}$ \\
\hline 0 & 38 & $3.8 \pm 1.6$ & $7.2 \pm 4.0$ & $4.2 \pm 4.4$ & $3.0 \pm 1.7$ \\
6 & 34 & $3.4 \pm 2.0 \ddagger$ & $6.1 \pm 4.4 \ddagger$ & $3.7 \pm 4.7 \ddagger$ & $2.4 \pm 1.8 \dagger$ \\
12 & 30 & $3.0 \pm 1.7 \ddagger$ & $5.4 \pm 4.5 \ddagger$ & $3.2 \pm 5.0 \ddagger$ & $2.2 \pm 1.7 \ddagger$ \\
18 & 30 & $2.9 \pm 1.8 \ddagger$ & $5.3 \pm 4.4 \ddagger$ & $3.4 \pm 5.0 \ddagger$ & $1.9 \pm 1.5 \ddagger$ \\
24 & 19 & $3.6 \pm 2.9 \mathrm{NS}$ & $6.2 \pm 5.5 \ddagger$ & $3.6 \pm 6.1 \ddagger$ & $2.6 \pm 1.9 \dagger$ \\
36 & 15 & $3.3 \pm 1.2 \mathrm{NS}$ & $6.1 \pm 5.6 \ddagger$ & $3.6 \pm 6.4 \ddagger$ & $2.5 \pm 2.1 \dagger$ \\
48 & 12 & $3.2 \pm 1.2 \mathrm{NS}$ & $5.3 \pm 2.5 \dagger$ & $3.0 \pm 3.2 \dagger$ & $2.3 \pm 1.8 \dagger$ \\
\hline
\end{tabular}

* $n=$ number of patients with adequate data for calculation at that time, not the number still available for follow-up.

$\dagger \mathrm{p}<0.005$ (Student's $t$-test)

$\pm \mathrm{p}<0.0005$ (Student's $t$-test)

NS Not significant

\section{RESULTS}

Postoperative course and complications. There was one superficial wound infection and one small haematoma in the popliteal fossa but neither of these caused more than transient inconvenience. No other postoperative complications were encountered. The average hospital stay was 4.7 days (range 3 to 10 days) and all children were fully weight-bearing on discharge.

Response to surgery. A positive response to surgery in our series was taken as the reversal of the pre-operative pattern of increasing percentage leg-length discrepancy. Using this criterion, all 38 patients had a satisfactory response at 12 months. The mean percentage difference in leg length dropped from $7.24 \%$ to $5.45 \%$ in the first year $(p<0.0005)$ and this represented a mean decrease in could expect $29 \%$ of cases still to be responding at three years; this agrees with the figure of $27 \%$ obtained above.

Although an end-point of the response to surgery was found at any time from two to five years after operation, all patients reviewed at four years still showed an improvement on their pre-operative value for percentage leg difference despite their return to a trend of increasing inequality.

Factors of value in predicting the response. We re-analysed our results to assess whether any factor of value in predicting the response to periosteal release could be identified. Figures were available for age at operation (including bone age in 15 cases), sex, diagnosis and rate of growth at operation as measured by the increase in corrected standing height over the previous 12 months. 
Table III. The effect of age on the response to surgery

\begin{tabular}{lllll}
\hline $\begin{array}{l}\text { Time } \\
\text { (months) }\end{array}$ & \multicolumn{2}{l}{ Mean decrease in total leg-length percentage difference } & Significance* \\
\cline { 2 - 5 } & Age 0-6y & Age 6-12y & Age 12+y & \\
\hline 6 & $1.57 \pm 1.13$ & $1.12 \pm 0.79$ & $0.23 \pm 0.50$ & 0.05 \\
12 & $2.44 \pm 0.88$ & $1.89 \pm 0.76$ & $0.55 \pm 0.36$ & 0.002 \\
18 & $2.91 \pm 0.99$ & $1.93 \pm 0.82$ & $0.73 \pm 1.03$ & 0.003 \\
24 & $3.03 \pm 0.57$ & $1.48 \pm 1.14$ & $0.35 \pm 0.86$ & 0.01 \\
36 & $2.97 \pm 0.56$ & $2.32 \pm 0.72$ & No data & N/A \\
48 & $2.32 \pm 1.09$ & $2.08 \pm 1.19$ & No data & N/A \\
\hline
\end{tabular}

* Analysis of variance

The only factor found to be of any significance was the age of the patient at operation (Fig. 2). The greatest response was seen in the age group 0 to 6 years and the least in the over- 12 group (Table III). Although accurate estimations of bone age were not available in all cases it does not appear from our results that it is of any greater predictive value than chronological age.

Response to a second periosteal release. The three patients who underwent a second periosteal release have each been followed for at least two years. Although the numbers involved are too small to make any definite predictions, all three cases have shown a further response to repeated surgery; the effect appears to be of slightly shorter duration than that of the original operation, lasting for between 18 months and two years.

\section{DISCUSSION}

Because of its lack of serious complications and its reliable effect we believe that circumferential periosteal release has a much wider application in the management of leg-length inequality than previously described procedures for growth stimulation. Many of these had either an unreliable effect on the growth of the limb or were associated with an unacceptably high level of complications. Barr et al., in 1950, found disappointing results with sympathetic ganglionectomy and in 1974 Petty et al. showed an adequate increase in growth in only $32 \%$ of patients treated by arteriovenous fistula, with significant long-term morbidity. Carpenter and Dalton in 1956, stimulated by the experimental work of Trueta (1951), attempted to increase growth by obliterating the metaphyseal intramedullary space with ivory chips, but they had very little success. Variations of the "foreign body" technique were published by Tupman in 1960 using beef bone pegs and by Castle in 1971 using a combination of screws and bone block, with $43 \%$ and $62 \%$ of patients respectively showing a satisfactory response. Both authors were disappointed with the lack of consistency of the results but in some of their patients a significant increase in growth was observed with minimal complications. Jenkins et al. (1975) showed that, in patients with leg-length discrepancy due to poliomyelitis, longitudinal periosteal stripping produced a satisfactory increase in growth in 17 of 30 patients. No procedure was performed on the fibula in that series and 18 patients were observed to develop a valgus deformity at the ankle.

Circumferential division of the periosteum compares favourably with all these series as it produces a reliably beneficial effect with minimal complications and is easily performed on both tibia and fibula, thus avoiding problems of a valgus ankle. It is tempting to speculate that, in the successful cases of other authors' series, the response was due to inadvertent circumferential division of the periosteum at the time of surgery, but no proof for this hypothesis can be offered.

The response to stimulation is greater in the younger children of our series and this may indicate their greater growth potential at this age. Previous authors have also found a better response in younger children (Tupman 1960; Castle 1971). Shiu and Wong (1964) found that there was an increased response to longitudinal periosteal stripping in five-week-old rabbits' tibiae compared with those of three-week or 10-week-old animals. They

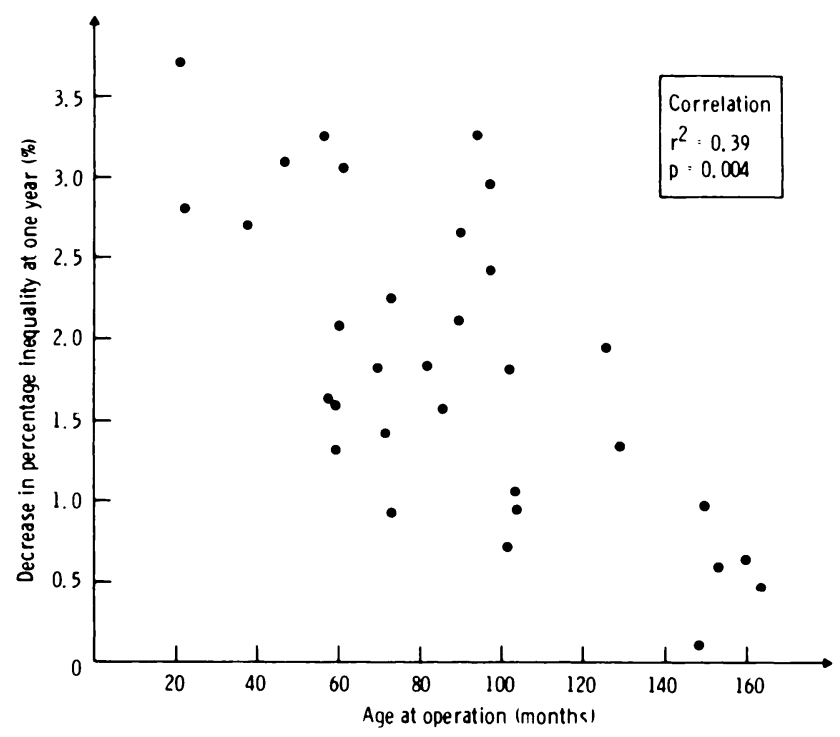

Fig. 2

Relationship of age at operation to the response to surgery expressed as the decrease in percentage inequality at one year. 
related this to the faster rate of growth of the animals at five weeks and suggested that reference to human skeletal growth charts could determine the optimum time for growth stimulation in the clinical situation. Our results do not confirm this extrapolation from the animal model, as in our study there was no correlation between the rate of growth at the time of surgery and the response to operation.

The mechanism by which the effect of periosteal release is mediated is no nearer solution than when Crilly published his original results in 1972. Whether the vascular response to the surgical insult, the diversion of metaphyseal blood flow, or the periosteal tension theory proposed by Crilly is responsible, is still unresolved. Certainly the periosteum is under tension as demonstrated by the fact that, after circumferential division, its cut edges are seen immediately to retract from the line of incision, but whether this represents a degree of tension sufficient to limit growth is still unresolved.

In our experience two groups of patients have benefited from this procedure. Firstly, there are the very young patients with disorders causing progressive leglength inequality, such as upper femoral growth disturbance or congenital abnormalities of the lower limb. In these patients periosteal release can provide a means of holding the discrepancy at a manageable level during childhood until they are at an age suitable for structural leg-lengthening or epiphyseal arrest. In these patients the final leg discrepancy requiring correction will then be reduced, making the definitive procedure less distressing for both the child and the surgeon.

Secondly, there are the children who have a mild degree of leg inequality ( $3 \mathrm{~cm}$ or less) as they enter adolescence and who might therefore require surgical correction of their inequality by maturity. In these patients periosteal release can be used to prevent the discrepancy from progressing and therefore decrease the likelihood of more complicated surgery becoming necessary in later life.

Conclusions. Circumferential periosteal release has been shown to be a reliable and safe means of growth stimulation in the child with leg-length inequality. The response to stimulation is inversely proportional to the age of the patient, being maximal in children under six years of age. We believe that this operation represents a valuable addition to the armamentarium of the surgeon engaged in the treatment of leg-length inequality.

The authors wish to acknowledge the extensive help and advice of Dr J. C. Pearson with the statistical analysis of the data.

\section{REFERENCES}

Baker GCW. Periosteal division in the management of the short leg in childhood. J Bone Joint Surg [Br] 1984;66-B:276.

Barr JS, Stinchfield AJ, Reidy JA. Sympathetic ganglionectomy and limb length in poliomyelitis. J Bone Joint Surg [Am] 1950:32-A:793-802.

Blount WP. Unequal leg length in children. Surg Clin North Am 1958:38:1107-23.

Carpenter EB, Dalton JB Jr. A critical evaluation of a method of epiphyseal stimulation. $J$ Bone Joint Surg [Am] 1956:38-A:1089-95.

Castle E. Epiphyseal stimulation. $J$ Bone Joint Surg [Am] $1971: 53-A: 326-34$.

Coldman AJ, Elwood JM. Examining survival data. Can Med Assoc J 1979:121:1065-8, 1071 .

Crilly RG. Longitudinal overgrowth of chicken radius. $J$ Anat 1972:112:11-8.

Doyle JR, Smart BW. Stimulation of bone growth by short-wave diathermy. J Bone Joint Surg [Am] 1963:45-A:15-24.

Houghton GR, Rooker GD. The role of the periosteum in the growth of long bones: an experimental study in the rabbit. J Bone Joint Surg [Br] 1979;61-B:218-20.

Jenkins DHR, Cheng DHF, Hodgson AR. Stimulation of bone growth by periosteal stripping: a clinical study. J Bone Joint Surg [Br] 1975:57-B :482-4.

Petty W, Winter RB, Felder D. Arteriovenous fistula for treatment of discrepancy in leglength. J Bone Joint Surg [Am] 1974:56-A :582-6.

Shiu MH, Wong WT. Periosteal stripping in the stimulation of longitudinal bone growth in rabbits. $J$ West Pacific Orthop Assoc $1964: 1: 241-6$

Solá CK, Silberman FS, Cabrini RL. Stimulation of longitudinal growth of long bones by periosteal stripping: an experimental study on dogs and monkeys. J Bone Joint Surg [Am] 1963:45-A:1679-84.

Taylor JF, Warrell E. The effect of local trauma on tibial growth. $J$ Bone Joint Surg [Br] 1977:59-B:503.

Trueta J. Stimulation of bone growth by redistribution of the intraosseous circulation. J Bone Joint Surg [Br] 1951 :33-B:476.

Tupman GS. Treatment of inequality of the lower limbs: the results of operations for stimulation of growth. J Bone Joint Surg [Br] 1960:42-B:489-501.

von Langenbeck B. Ueber krankhaftes Längenwachsthum der Röhrenknochen und seine Verwerthung für die chirurgische Praxis. Berl Klin Wochenschr 1869:6(26):265-70.

Wu YK, Miltner LJ. A procedure for stimulation of longitudinal growth of bone: an experimental study. J Bone Joint Surg $1937: 339: 909-21$ 